\title{
Total Knee Arthroplasty and Intra-Articular Pressure Sensors: Can They Assist Surgeons with Intra-Operative Decisions?
}

\author{
Liam Z. Yapp $^{1,2}$ (D) Patrick G. Robinson ${ }^{1,2} \cdot$ Nicholas D. Clement $^{1,2} \cdot$ Chloe E. H. Scott $^{1,2}$
}

Accepted: 22 September 2021 / Published online: 28 December 2021

(C) The Author(s) 2021

\begin{abstract}
Purpose of Review Soft tissue imbalance, presenting as instability or stiffness, is an important cause of revision total knee arthroplasty (TKA). Traditional methods of determining soft tissue balance of the knee lack precision and are not reliable between operators. Use of intra-operative pressure sensors offers the potential to identify and avoid soft tissue imbalance following TKA. This review aims to summarise the literature supporting the clinical indication for the use of intra-articular pressure sensors during TKA.

Recent Findings Analytical validation studies suggest that intra-operative pressure sensors demonstrate 'moderate' to 'good' intra-observer reliability and 'good' to 'excellent' interobserver reliability throughout the flexion arc. However, there are important errors associated with measurements when devices are used out-with the stated guidelines and clinicians should be aware of the limitations of these devices in isolation. Current evidence regarding patient benefit is conflicting. Despite positive early results, several prospective studies have subsequently failed to demonstrate significant differences in overall survival, satisfaction, and patient-reported outcome measures within 1 year of surgery.

Summary Surgeon-defined soft tissue stability appears to be significantly different from the absolute pressures measured by the intra-operative sensor. Whilst it could be argued that this confirms the need for intra-articular sensor guidance in TKA; the optimal 'target' balance remains unclear and the relationship with outcome in patients is not determined. Future research should (1) identify a suitable reference standard for comparison; (2) improve the accuracy of the sensor outputs; and (3) demonstrate that sensor-assisted TKA leads to patient benefit in patient-reported outcome measures and/or enhanced implant survival.
\end{abstract}

Keywords Knee $\cdot$ Arthroplasty $\cdot$ Soft tissue $\cdot$ Balance $\cdot$ Sensor $\cdot$ Outcome

This article is part of the Topical Collection on The Use of Technology in Orthopaedic Surgery - Intraoperative and Post Operative Management

Liam Z. Yapp

liam.yapp@nhslothian.scot.nhslothian.uk;

liam.yapp@nhslothian.scot.nhs.uk

Patrick G. Robinson

patrick.robinson@nhslothian.scot.nhs.uk

Nicholas D. Clement

Nick.clement@nhslothian.scot.nhs.uk

Chloe E. H. Scott

Chloe.scott@nhslothian.scot.nhs.uk

1 Department of Orthopaedics, Deanery of Clinical Sciences, University of Edinburgh, Chancellors Building, 49 Little France Crescent, Edinburgh EH16 4SB, UK

2 Department of Trauma \& Orthopaedic Surgery, Royal Infirmary of Edinburgh, NHS Lothian, 51 Little France Crescent, Edinburgh EH16 4SY, UK

\section{Introduction}

A sensor is broadly defined by the Oxford Dictionary as a 'device which detects or measures a physical property and records, indicates or otherwise responds to it'. Biometric Monitoring Technologies (BioMeTs) are digital medicine devices which process medical or health data captured by mobile sensors $\left[1^{\bullet}\right]$. Using data-driven algorithms, BioMeTs generate measures of behavioural and/or physiological function.

The purpose of any technology used to assist a surgical procedure is to enhance operator precision, reduce the presence of outliers and to improve patient outcome [2]. Rather than relying entirely on subjective interpretation, sensorassisted surgery aims to provide quantifiable information which can supplement the experience of the surgeon [3].

Although there are examples of biomechanical studies utilising implantable sensors in surgery of the spine, hip, and 
shoulder [4, 5], few clinical studies involving these devices have been undertaken. Conversely, in recent years there has been an increasing interest in sensor-assisted soft tissue balancing in primary total knee arthroplasty (TKA). Accordingly, this review will focus on the current uses and evidence base surrounding sensor-assisted TKA surgery.

\section{Background}

Arthritis is a major global cause of adult disability and it is reported that over 300 million people are affected by either hip or knee osteoarthritis [6]. The lifetime risk of symptomatic knee osteoarthritis is estimated to be as high as $44.7 \%$ [7]. A significant proportion of these patients will require total knee arthroplasty (TKA) if their symptoms of pain and disability are not controlled adequately by simple measures such as activity modification and analgesia $[8,9]$.

TKA is associated with a successful outcome in the majority of cases; however, approximately one in five patients will not be satisfied following surgery $[10,11]$. Many factors influence the outcome of primary knee arthroplasty and may be broadly classified as patient [12-14], surgical [15], or system factors $[16,17]$. It is reported that up to $7-24 \%$ of revision TKAs are performed for soft tissue imbalance in the form of joint instability $[15,18,19]$. Accordingly, there is increasing focus on techniques that can improve instability-related factors such as overall limb alignment, implant positioning, flexion-extension balance of the knee, and management of the soft tissue envelope [20].

\section{Rationale for Sensor-Assisted Total Knee Arthroplasty}

Insall advocated altering the native knee's anatomical alignment to pursuing neutral mechanical alignment through positioning the femoral and tibial implants perpendicular to the mechanical axis of the limb [21]. This would distribute the load transmitted through the knee more evenly and avoid complications such as uneven polyethylene wear which can lead to early failure. To achieve this, the tibia is cut in zero degrees to enable the mechanical axis to pass through the centre of the knee joint. In order to balance the flexion gap, the femur is positioned in 3 degree of external rotation to compensate for the relative valgus position of the tibial component.

More recently there has been increasing interest in pursuing a more anatomical, or kinematic, alignment of the knee [22]. This method attempts to recreate the normal tibio-femoral joint articulation and places the tibial and femoral component axes in alignment with the three kinematic axes of the "normal' knee. In theory, kinematic alignment is more patient- specific and should require minimal soft tissue releases as bone cuts are symmetrical for medial and lateral compartments [23]. Using sensor-reported pressures as a primary outcome measure, MacDessi et al. [24] demonstrated in a randomised control trial (RCT) of kinematic versus mechanical alignment that restoring the constitutional alignment with kinematic alignment in TKA resulted in a statistically significant improvement in knee balance with less difference in pressure between medial and lateral compartments and less need for recuts or releases. However, as this technique ignores the overall limb alignment in the coronal plane, there are fears that KA will create varus-valgus outliers and therefore contribute to early failure [25]. Although much research has been undertaken to identify which technique provides the optimal outcome for patients, no convincing conclusions regarding superiority have been drawn [26-28].

Navigation, robotic systems, and patient-specific instruments have added objectivity and precision to help define a more functional alignment and anatomic rotation when performing TKA [23, 29]. However, the concept of soft tissue balance continues to be principally determined by the subjective 'feel' of the surgeon [30]. This can be affected by overall surgeon experience, operative technique, and patient-specific variables such as body mass index (BMI), gender, co-morbidity, and relative ligamentous laxity [20]. Whilst many surgeons agree that it is important, the definition of a balanced TKA appears to be contentious and often hard to define [31]. It is perhaps understandable that intra-operative surgeon assessment has been shown to be highly inaccurate and a poor predictor of TKA balance [32•].

Intra-articular sensor-based balancing can provide dynamic, intra-operative feedback for the surgeon regarding overall tibio-femoral contact point, kinematic tracking, and pressure monitoring in areas of peak contact in the medial and lateral compartments of the knee $[25,30,33]$. Compared to traditional gap balancing techniques, sensor-based TKA allows the patella to be reduced during measurements whereas tensiometers do not [34]. This is relevant as it avoids the extensor mechanism acting as a lateral tether, which may inadvertently affect compartmental loads, and enables accurate tibiofemoral tracking. In theory, this data can be used by the operating surgeon to correct soft tissue imbalance in a controlled, targeted, and quantifiable fashion.

\section{Evaluation of Intra-Operative Sensors Used To Balance TKA}

A key element of evaluating a diagnostic test ('index test') is to determine its diagnostic accuracy, i.e. the ability of the test to discriminate between patients with and without the target condition [35]. In ideal conditions, assessment of diagnostic accuracy relies upon a 'gold standard' reference which can 
accurately identify whether the target condition is present or not [36]. However, as is the case with many medical conditions, there is no error-free 'gold standard' available to determine intra-articular soft tissue knee balance. In such situations, researchers will use the best available method to determine the presence or absence of the target condition, often termed the 'reference standard' $[37,38]$.

The definition of soft tissue balance of the knee is poorly defined with little consensus available in the literature [31]. When the gold standard is absent, and the diagnostic accuracy of the reference standard is unknown, current guidance suggests undertaking alternative methods of assessment such as test validation and analytical sensitivity $[37,38]$. Such methods assess how accurate the 'index test' is at measuring what it is designed to measure.

All diagnostic tests, including BioMeTs, should be systematically evaluated to verify and validate their findings [37-39]. Goldsack et al. [1•] recently described a three-component framework-verification, analytical validation, and clinical validation (V3) - which can be used to evaluate BioMeTs in digital medicine (Table 1).

\section{Intra-Operative Technique and Supporting Evidence}

To the authors' knowledge at present, there are two commercially available sensor-guided intra-operative soft tissue balancing technologies for TKA: the VERASENSE Knee System (OrthoSensor, Dania FL, USA) and the eLIBRA Dynamic Knee Balancing System (Synvasive Technology, Zimmer-Biomet, Reno, NV, USA). Both systems employ single-use, modular components which are designed to provide real-time quantifiable feedback during the surgeon's standard approach to TKA with minimal workflow disruption. The following sections will focus on the analytical and clinical validation of pressure sensors in TKA.

\section{VERASENSE Knee System (KS)}

The VERASENSE KS has been developed with microelectronics embedded into a single-use modular tibial trial component [33]. The VERASENSE KS sensor communicates wirelessly with an OrthoSensor LinkStation which is uploaded with software which can interpret the measurements as compressive loads displayed in pounds (lb) and feeds this back to the operating surgeon using a visual display.

The VERASENSE KS was originally available to be used with three companies' implants (Stryker: Triathlon®; Zimmer-Biomet: Persona ${ }^{\circledR}, \mathrm{NexGen} \AA$, and Vanguard $\AA$; and Smith \& Nephew: Legion ${ }^{\circledR}$ and Journey II®). Following full bony resection of the femur and tibia, the trial components are inserted, and manually assessed by the operating surgeon. A VERASENSE KS component can then replace the trial polyethylene insert and shims are inserted to mimic the desired polyethylene thickness. Upon activation of the component, the tibial component is positioned and held with static pins before the capsule is temporarily closed with clips. The knee is then put through a full range of motion to assess tibial rotation and soft tissue tension. This provides medial and lateral tibiofemoral contact forces and points of contact to be recorded as the knee is passively flexed to $10^{\circ}, 45^{\circ}$, and $90^{\circ}$. Based on the feedback provided, the operating surgeon can then choose whether soft tissue releases of either the medial or lateral structures or further bony resection are required.

\section{eLIBRA Dynamic Knee Balancing System (DKBS)}

The eLIBRA DKBS is only designed for Zimmer-Biomet knee implants (Vanguard ${ }^{\circledR}$ and Persona ${ }^{\circledR}$ ). It has femoral and tibial components which can be adjusted to suit the needs of each patient. The tibial sensor sits beneath the trial tibial component and is attached to a handle with an electronic display. Compressive forces are displayed as units (ranging between 1 and 20$)$ equating to approximately $15 \mathrm{~N}(3.4 \mathrm{lb})$ per unit.

Table 1 The stages of V3 for a BioMeT (adapted from Goldsack et al. [1•])

\begin{tabular}{|c|c|c|c|c|}
\hline Step & Component & Description & Responsibility & Example question \\
\hline 1 & Verification & $\begin{array}{l}\text { Systematic evaluation of sensor performance and the generated } \\
\text { sample-level data against pre-specified criteria. }\end{array}$ & Manufacturer & $\begin{array}{l}\text { Is the raw data from the pressure sensor accurate, } \\
\text { precise, and consistent? }\end{array}$ \\
\hline 2 & $\begin{array}{l}\text { Analytical } \\
\text { validation }\end{array}$ & $\begin{array}{l}\text { Evaluates algorithm performance and ability of BioMeT to } \\
\text { measure, detect, or predict physiological metrics }\end{array}$ & $\begin{array}{l}\text { Manufacturer } \\
\text { Sponsor } \\
\text { Clinical } \\
\quad \text { researchers }\end{array}$ & $\begin{array}{l}\text { Does the pressure sensor and processing } \\
\text { algorithms provide clinical-grade accuracy of } \\
\text { intra-compartmental pressures? }\end{array}$ \\
\hline 3 & $\begin{array}{l}\text { Clinical } \\
\text { validation }\end{array}$ & $\begin{array}{l}\text { Evaluates whether BioMeT acceptably identifies, measures, or } \\
\text { predicts a meaningful clinical, biological, physical, } \\
\text { functional state or experience in the stated context of use } \\
\text { (which includes a specified population) }\end{array}$ & $\begin{array}{l}\text { Sponsor } \\
\text { Clinical } \\
\quad \text { researchers }\end{array}$ & $\begin{array}{l}\text { Do intra-compartmental pressures detect soft } \\
\text { tissue imbalance of the knee? } \\
\text { Does adjustment of intra-compartmental } \\
\text { pressures predicts knee joint stability? }\end{array}$ \\
\hline
\end{tabular}


Unlike the VERASENSE KS, the eLIBRA DKBS is used after the extension gap is produced following distal femoral and proximal tibia resection. The LIBRA Femoral Component is then positioned and secured against the distal femur with respect to the centre of the intercondylar notch and the posterior femoral condyles. Once the LIBRA Femoral Component is satisfactorily positioned, the corresponding sized eLIBRA tibial insert is chosen and the sensor is activated. The patella is then reduced to ensure all dynamic forces are considered and the knee is flexed to 90 degrees. The medial load is then demonstrated by a number on the sensor handle electronic display. The tibial sensor values should range from 4 to 9 (i.e. 13.6-30.6 lb) on the medial side. If the medial loads are lower than 4 (i.e. $<13.6 \mathrm{lb}$ ), a thicker tibial insert is required. If the medial load is higher than a 9 (i.e. $>30.6 \mathrm{lb}$ ), a thinner insert is required with or without additional soft tissue releases and further tibial resection.

Once the target medial load is achieved, the insert height has been established and attention can be turned to adjustment of the articulating LIBRA femoral component. Using the adjustment mechanism, the lateral posterior femoral condyle is elevated (and thereby externally rotated up to a maximum of 10 degrees) with the intention to equalise the relative forces in the medial and lateral tibio-femoral compartments. Once satisfactorily balanced, the remaining femoral resection is performed, and the procedure completed as per the standard implant surgical technique.

\section{Analytical Validation-Are the Pressure Sensors Used in TKA Accurate and Reliable?}

Several cadaveric, biomechanical, and clinical studies have been undertaken investigating the potential utility of pressure sensors in TKA. Collateral ligament and intra-compartment contact forces measured during TKA have shown significant correlation and a linear relationship has been demonstrated throughout the flexion arc [40]. This would suggest that quantitative measurement of condylar contact forces is a suitable alternative for the measurement of soft tissue balance of the knee.

The VERASENSE KS manufacturers advise a measurement range of 5-40 lb force per compartment and a maximum force of $70 \mathrm{lb}$ per compartment. In the event that pressures exceed the maximum value, the device should be removed and re-zeroed prior to reuse. In light of these recommendations, Nicolet-Peterson et al. [41] evaluated the accuracy of tibial contact force measurements and location errors. When computing the worst-case scenario for values out-with the acceptable range of loading, the bias, precision, and rootmean-square error (RMSE) for tibial contact force imbalance were $0 \mathrm{lb}, 4.4 \mathrm{lb}$, and $4.4 \mathrm{lb}$ force respectively. Furthermore, when loading occurred outside the sensing area in one compartment, the error was increased leading to inaccurate tibial contact force and contact location measurements. If an intracompartmental force difference of less than $15 \mathrm{lb}$ is targeted, then the VERASENSE KS force measurements could exceed this value $16 \%$ of the time, despite the knee achieving the target imbalance [41]. This could result in unnecessary soft tissue releases in approximately one in seven patients. The authors suggest that surgeons should be cautious in the interpretation of the VERASENSE KS readings and use it to supplement their clinical experience.

Pressure sensors used in TKA appear to be reliable on repeat testing and between observers. Test-retest load measurements have been shown to be less than $3 \mathrm{lb}(1.4 \mathrm{~kg})$ across multiple knees [42]. The intra-observer agreement varied between moderate to good in the majority of measurements, in both a blinded and unblinded setting [43]. However, the lowest level of agreement was observed at 10 degrees of flexion (medial intra-class correlation (ICC) $0.52,95 \%$ CI $0.20-0.74$; lateral ICC $0.64,95 \%$ CI $0.38-0.81$ ). Conversely, Thompson et al. [44] demonstrated using Bland-Altman plots that excellent interobserver agreement of VERASENSE measurements was noted at 10 degrees flexion, but noted that this agreement decreased with increasing flexion. However, interobserver agreement showed ICC values ranging between good and excellent reliability for medial compartment pressures measured at 10 degrees $(0.93,95 \%$ CI $0.89-0.95), 45$ degrees $(0.91,95 \%$ CI $0.87-0.93)$, and 90 degrees of flexion $(0.88$, 95\% CI 0.83-0.91) [44]. Similarly, the ICC for lateral compartment pressure measures was excellent (ICC $0.91,95 \%$ CI $0.87-0.93$ ) at 10 degrees, and good for both 45 degrees (ICC $0.76,95 \%$ CI $0.68-0.82$ ) and 90 degrees flexion (ICC 0.76 , 95\% CI 0.67-0.82).

Sensor assistance has also improved the understanding of how surgical technique can influence intra-compartmental loads. Manning et al. [45] investigated the role of femoral component position on medial and lateral compartment pressures. These authors found no difference in the loading patterns of either compartment in a neutral knee across the entire flexion arc. Interestingly, whilst an internally rotated femoral component led to very high medial compartment pressures over 60 degrees of flexion without instability, externally rotating the femoral component did not produce a similar outcome in the lateral compartment.

In a cadaveric study utilising computer navigation and sensor assistance, rotation of the tibial component has also been shown to alter the forces through the medial compartment of the knee [46]. These findings suggest that external rotation of the tibial tray could potentially lead to early failure of the medial compartment polyethylene. However, external rotation of the tibial component did not alter knee laxity during flexion when compared with neutral rotation.

Sensor-assisted TKA may also enable clinicians to perform soft tissue releases in a controlled and safe manner. Step-wise puncturing of the medial collateral ligament (MCL) has been 
shown to significantly reduce the medial compartment pressures and correlated significantly with joint gap measurement [47]. Whether step-wise puncturing alters laxity postoperatively in the longer term remains unclear as this technique is used for arthroscopic meniscal surgery without being complicated by persistent MCL laxity [48].

\section{Clinical Validation-What Is a Balanced TKA?}

When adhering to manufacturer guidance, measurement of inter-compartment forces has been shown to be accurate and reliable between users. However, one major issue is how to interpret absolute pressure values and the inter-compartmental difference. The developers of VERASENSE suggest that the knee is considered to be balanced when it satisfies the following criteria [3]: (1) The joint must be stable in the sagittal plane, demonstrated by a stable end-point during application of a posterior drawer test; and (2) the respective compressive loads in the medial and lateral compartments of the knee are below 55 and $45 \mathrm{lb}$, with an intra-compartmental difference of less than $15 \mathrm{lb}$.

Gustke et al. [3] reported that this latter cutoff value was chosen based upon previous biomechanical research into intercondylar compartmental pressures [49], and intraoperative observation of 'experienced' surgeons following varus-valgus stress testing of the knee of $2 \mathrm{~mm}$ using computer-assisted navigation. A further association with postoperative improvement in the original American Knee Society Score (KSS) was reported; however, it was subsequently confirmed that this was a post hoc finding [50].

Meneghini and colleagues [51] attempted to validate this target ligament balance by performing a multi-centre retrospective case-series in which the VERASENSE KS was used to measure intra-compartmental pressures during TKA, but was not used to guide soft tissue balancing. These authors found no association with intra-compartmental force and patient-reported function or satisfaction scores concluding that the 'less than $15 \mathrm{lb}$ ' cutoff was arbitrary and may not evidence-based.

Meere et al. [52] suggested a balanced approach, using a ratio of the medial force to the total force, aiming for a ratio of 0.5 if both compartments were equally matched. Prior to balancing, the contact force ratio went from $0.49 \pm 0.27$ to $0.52 \pm 0.14$. These authors considered a contact force ratio between 0.35 and 0.65 to be 'acceptable' based upon subjective assessment of knee balance. Subsequent studies utilising this ratio found no correlation between the contact force ratio and knee society scores of symptoms, satisfaction, and function [53].

Jacobs et al. [54] used the eLIBRA to determine whether symmetrical forces across the medial and lateral compartments had greater correlation with satisfaction and other patient-reported outcome measures (PROMs). These authors converted their results to pounds, thereby enabling their results to be viewed in the context of the VERASENSE KS. They reported a greater proportion of satisfied patients among those who exhibited greater forces in the medial compartment, which may be explained as this is thought to be similar to the pattern of contact forces observed in the native knee [55].

Shelton et al. [56 $6^{\bullet}$ looked at the range of published force targets $[50-52,54]$ and found no association with outcome in patients undergoing kinematically aligned TKA. Despite these findings, the majority of research [24, 42, 43, 57, 58, 59・•, 60-62] related to the VERASENSE KS continues to use the cutoff of inter-compartment difference of less than $15 \mathrm{lb}$ [3].

\section{Clinical Validation-Sensor-Assisted TKA and Outcomes}

Surgeon-defined soft tissue stability, either determined by 'feel' or through use of a tensiometer during TKA, appears to be significantly different from the absolute pressures measured by the intra-operative sensor $[30,63]$. Whilst it could be argued that this confirms the need for intra-operative sensor guidance in TKA, the optimal 'target' balance however remains unclear and the relationship with outcome in patients is yet to be determined.

It is hoped that improving soft tissue balance will result in enhanced PROMs and longer duration of implant survival. No difference has been reported in overall complications or revision within 1 year [51, 59••, 64]. To date, there are no studies comparing implant survival of sensor-assisted versus manual TKA beyond 2 years.

Current evidence regarding patient-reported outcomes is conflicting. Two industry-sponsored reports suggested that 'balanced' knees were associated with greater improvement in PROMs and satisfaction [50, 65]. However, several retrospective and prospective studies have subsequently failed to demonstrate any significant difference in overall satisfaction, knee-specific outcomes, and general health-related quality of life measures at 6 and 12 months [42, 51, 56•, 59••, 62, 64, 66]. These findings could suggest that the current 'target' balance utilised by most authors is either incorrect or at the very least too narrow to identify a difference. In the absence of evidence demonstrating improved implant survival or enhanced PROMs, it is not possible to report on the costeffectiveness of sensor-assisted TKA.

\section{Areas for Future Development}

There are fundamental elements regarding the diagnostic and clinical validity of commercially available pressure sensors used in TKA which are yet to be determined. Future research should be focussed on the following areas: (1) identification of a suitable reference standard for comparison; (2) improve the 
accuracy of the sensor outputs; (3) demonstration that sensorassisted TKA leads to patient benefit in PROMs and/or enhanced implant survival.

\section{Conclusions}

Soft tissue imbalance, presenting as instability or stiffness, is an important cause of revision TKA. Traditional methods of determining soft tissue balance of the knee are not defined and are not reliable between operators. Use of intra-operative sensors offers the potential to identify, predict, and avoid soft tissue imbalance following TKA. To enhance our understanding of the utility of currently available devices, future research should (1) identify a suitable reference standard for comparison; (2) improve the accuracy of the sensor outputs; and (3) demonstrate that sensor-assisted TKA leads to patient benefit in patient-reported outcome measures and/or enhanced implant survival.

\section{Declarations}

Human and Animal Rights and Informed Consent This article does not contain studies with human or animal subjects performed by any of the authors.

Conflict of Interest All authors declare that they have no conflict of interest to report.

Open Access This article is licensed under a Creative Commons Attribution 4.0 International License, which permits use, sharing, adaptation, distribution and reproduction in any medium or format, as long as you give appropriate credit to the original author(s) and the source, provide a link to the Creative Commons licence, and indicate if changes were made. The images or other third party material in this article are included in the article's Creative Commons licence, unless indicated otherwise in a credit line to the material. If material is not included in the article's Creative Commons licence and your intended use is not permitted by statutory regulation or exceeds the permitted use, you will need to obtain permission directly from the copyright holder. To view a copy of this licence, visit http://creativecommons.org/licenses/by/4.0/.

\section{References}

Papers of particular interest, published recently, have been highlighted as:

- Of importance

- Of major importance

1. Goldsack JC, Coravos A, Bakker JP, Bent B, Dowling AV, FitzerAttas C, et al. Verification, analytical validation, and clinical validation (V3): the foundation of determining fit-for-purpose for Biometric Monitoring Technologies (BioMeTs). NPJ Digit Med.
2020;3(1) This study outlines the key elements which must be evaluated when assessing any biometric monitoring technology.

2. Zheng G, Tian W, Zhuang X, editors. Intelligent orthopaedics artificial intelligence and smart image-guided technology for orthopaedics. Vol. 1093, Advances in Experimental Medicine and Biology. Springer; 2018. 1-335 p.

3. Gustke KA, Golladay GJ, Roche MW, Elson LC, Anderson CR. A new method for defining balance: promising short-term clinical outcomes of sensor-guided TKA. J Arthroplast. 2014;29(5):95560 .

4. Ledet EH, Liddle B, Kradinova K, Harper S. Smart implants in orthopedic surgery, improving patient outcomes: a review. Innov Entrep Heal. 2018;5:41-51.

5. D'Lima DD, Fregly BJ, Colwell CW. Implantable sensor technology: Measuring bone and joint biomechanics of daily life in vivo. Arthritis Res Ther. 2013;15(1):1-8.

6. Safiri S, Kolahi AA, Smith E, Hill C, Bettampadi D, Mansournia MA, Hoy D, Ashrafi-Asgarabad A, Sepidarkish M, AlmasiHashiani A, Collins G, Kaufman J, Qorbani M, Moradi-Lakeh M, Woolf AD, Guillemin F, March L, Cross M. Global, regional and national burden of osteoarthritis 1990-2017: a systematic analysis of the Global Burden of Disease Study. Ann Rheum Dis. 2017;2020:819-28.

7. Murphy L, Schwartz TA, Helmick CG, Renner JB, Tudor G, Koch G, Dragomir A, Kalsbeek WD, Luta G, Jordan JM. Lifetime risk of symptomatic knee osteoarthritis. Arthritis Rheum. 2008;59(9): 1207-13.

8. Burn E, Murray DW, Hawker GA, Pinedo-Villanueva R, PrietoAlhambra D. Lifetime risk of knee and hip replacement following a GP diagnosis of osteoarthritis: a real-world cohort study. Osteoarthr Cartil. 2019;27(11):1627-35.

9. Culliford DJ, Maskell J, Kiran A, Judge A, Javaid MK, Cooper C, Arden NK. The lifetime risk of total hip and knee arthroplasty: results from the UK general practice research database. Osteoarthr Cartil. 2012;20(6):519-24.

10. Scott CEH, Howie CR, MacDonald D, Biant LC. Predicting dissatisfaction following total knee replacement: a prospective study of 1217 patients. J Bone Joint Surg (Br). 2010;92(9):1253-8.

11. Clement ND, Bardgett M, Weir D, Holland J, Gerrand C, Deehan DJ. Three groups of dissatisfied patients exist after total knee arthroplasty: early, persistent, and late. Bone Joint J. 2018;100B(2):161-9.

12. Yapp LZ, Clement ND, Macdonald DJ, Howie CR, Scott CEH. Changes in expectation fulfillment following total knee arthroplasty: a 10-year follow-up study. J Arthroplast. 2020;35(7): 1826-32.

13. Al-Hourani K, MacDonald DJ, Turnbull GS, Breusch SJ, Scott $\mathrm{CEH}$. Return to work following total knee and hip arthroplasty: the effect of patient intent and preoperative work status. J Arthroplast. 2020 Aug;10:434-41.

14. Baker PN, van der Meulen JH, Lewsey J, Gregg PJ. The role of pain and function in determining patient satisfaction after total knee replacement. Data from the national joint registry for England and Wales. J Bone Joint Surg (Br). 2007;89(7):893-900.

15. Jorgensen NB, McAuliffe M, Orschulok T, Lorimer MF, De Steiger R. Major aseptic revision following total knee replacement: a study of 478,081 total knee replacements from the Australian Orthopaedic Association National Joint Replacement Registry. J Bone Jt Surg - Am Vol. 2019;101(4):302-10.

16. Liddle AD, Pandit H, Judge A, Murray DW. Optimal usage of unicompartmental knee arthroplasty: a study of 41986 cases from the national joint registry for England and Wales. Bone Joint J. 2015;97B(11):1506-11.

17. Jeschke E, Citak M, Günster C, Matthias Halder A, Heller KD, Malzahn J, et al. Are TKAs performed in high-volume hospitals 
less likely to undergo revision than TKAs performed in low-volume hospitals? Clin Orthop Relat Res. 2017;475(11):2669-74.

18. Sharkey PF, Lichstein PM, Shen C, Tokarski AT, Parvizi J. Why are total knee arthroplasties failing today-has anything changed after 10 years? J Arthroplast. 2013;29(9):1774-8.

19. Pitta M, Esposito CI, Li Z, Yu LY, Wright TM, Padgett DE. Failure after modern total knee arthroplasty: a prospective study of 18,065 knees. J Arthroplast. 2018;33(2):407-14.

20. Song SJ, Detch RC, Maloney WJ, Goodman SB, Huddleston JI. Causes of instability after total knee arthroplasty. J Arthroplast. 2014;29(2):360-4

21. Hood RW, Vanni M, Insall JN. The correction of knee alignment in 225 consecutive total condylar knee replacements. Clin Orthop Relat Res. 1981;160:94-105.

22. Howell SM, Howell SJ, Kuznik KT, Cohen J, Hull ML. Does a kinematically aligned total knee arthroplasty restore function without failure regardless of alignment category? Knee Clin Orthop Relat Res. 2013;471(3):1000-7.

23. Oussedik S, Abdel MP, Victor J, Pagnano MW, Haddad FS. Alignment in total knee arthroplasty. Bone Joint J. 2020;102 B(3):276-9.

24. MacDessi SJ, Griffiths-Jones W, Chen DB, Griffiths-Jones S, Wood JA, Diwan AD, Harris IA. Restoring the constitutional alignment with a restrictive kinematic protocol improves quantitative soft-tissue balance in total knee arthroplasty: a randomized controlled trial. Bone Joint J. 2020;102(1):117-24.

25. Shelton TJ, Nedopil AJ, Howell SM, Hull ML. Do varus or valgus outliers have higher forces in the medial or lateral compartments than those which are in-range after a kinematically aligned total knee arthroplasty? Bone Joint J. 2017;99B(10):1319-28.

26. Waterson HB, Clement ND, Eyres KS, Mandalia VI, Toms AD. The early outcome of kinematic versus mechanical alignment in total knee arthroplasty: a prospective randomised control trial. Bone Joint J. 2016;98-B(10):1360-8.

27. Roussot MA, Vles GF, Oussedik S. Clinical outcomes of kinematic alignment versus mechanical alignment in total knee arthroplasty: a systematic review. EFORT Open Rev. 2020;5:486-97.

28. Dossett HG, Estrada NA, Swartz GJ, Lefevre GW, Kwasman BG. A randomised controlled trial of kinematically and mechanically aligned total knee replacements. Bone Jt J. 2014;96-B(7):907-13.

29. Roberts TD, Frampton CM, Young SW. Outcomes of computerassisted surgery compared with conventional instrumentation in 19, 221 total knee arthroplasties. J Bone Jt Surg. 2020;102(7):550-6.

30. Elmallah RK, Mistry JB, Cherian JJ, Chughtai M, Bhave A, Roche MW, Mont MA. Can we really "feel" a balanced total knee arthroplasty? J Arthroplast. 2016;31(9):102-5.

31. Walker LC, Clement ND, Ghosh KM, Deehan DJ. What is a balanced knee replacement? EFORT Open Rev. 2018;3(12):614-9.

32. MacDessi SJ, Wood JA, Diwan AD, Harris IA, Bhimani A, Burns AWR, et al. Surgeon-defined assessment is a poor predictor of knee balance in total knee arthroplasty: a prospective, multicenter study. Knee Surg Sports Traumatol Arthrosc. 2021;29(2):498-506 Study demonstrates that surgeon-defined assessment lacks objectivity and precision when assessing soft tissue knee balance in total knee arthroplasty.

33. Gustke $\mathrm{K}$. Use of smart trials for soft-tissue balancing in total knee replacement surgery. J Bone Jt Surg - Ser B. 2012;94 B(11 SUPPL.A):147-50.

34. Sculco P, Gruskay J, Nodzo S, Carrol K, Shanaghan K, Haas S, Gonzalez Della Valle A. The role of the tourniquet and patella position on the compartmental loads during sensor-assisted total knee arthroplasty. J Arthroplast. 2018;33(7):S121-5.

35. Sackett DL, Haynes RB. Evidence base of clinical diagnosis: the architecture of diagnostic research. Br Med J. 2002;324(7336):539 41.
36. Leeflang MMG, Allerberger F. How to: evaluate a diagnostic test. Clin Microbiol Infect. 2019;25(1):54-9.

37. Chikere CMU, Wilson K, Graziadio S, Vale L, Allen AJ. Diagnostic test evaluation methodology: a systematic review of methods employed to evaluate diagnostic tests in the absence of gold standard - an update. PLoS One. 2019;14(10):1-25.

38. Reitsma JB, Rutjes AWS, Khan KS, Coomarasamy A, Bossuyt PM. A review of solutions for diagnostic accuracy studies with an imperfect or missing reference standard. J Clin Epidemiol. 2009;62(8):797-806.

39. Cohen JF, Korevaar DA, Altman DG, Bruns DE, Gatsonis CA, Hooft L, Irwig L, Levine D, Reitsma JB, de Vet HCW, Bossuyt PMM. STARD 2015 guidelines for reporting diagnostic accuracy studies: explanation and elaboration. BMJ Open. 2016;6(11):1-17.

40. Sanz-Pena I, Zapata GE, Verstraete MA, Meere PA, Walker PS. Relationship between ligament forces and contact forces in balancing at total knee surgery. J Arthroplast. 2019;34(6):1261-6.

41. Nicolet-Petersen SJ, Howell SM, Hull ML. Tibial contact force and contact location errors of the VERASENSE. J Biomech Eng. 2018;140(12):1-6.

42. Song SJ, Kang SG, Lee YJ, Il KK, Park CH. An intraoperative load sensor did not improve the early postoperative results of posteriorstabilized TKA for osteoarthritis with varus deformities. Knee Surg Sports Traumatol Arthrosc. 2019;27(5):1671-9.

43. van der Linde JA, Beath KJ, Leong AKL. The reliability of sensorassisted soft tissue measurements in primary total knee arthroplasty. J Arthroplast. 2018;33(8):2502-2505.e12.

44. Thompson K, Griffiths-Jones W, Frendin L, Wood J, Harris IA, Chen DB, MacDessi SJ. Interobserver agreement of sensorderived compartmental pressure measurements in computerassisted total knee arthroplasty. Knee. 2020;27(3):717-22.

45. Manning WA, Ghosh KM, Blain A, Longstaff L, Rushton SP, Deehan DJ. Internal femoral component rotation adversely influences load transfer in total knee arthroplasty: a cadaveric navigated study using the Verasense device. Knee Surg Sports Traumatol Arthrosc. 2018;26(5):1577-85.

46. Manning WA, Ghosh KM, Blain AP, Longstaff LM, Rushton SP, Deehan DJ. Does maximal external tibial component rotation influence tibiofemoral load distribution in the primary knee arthroplasty setting: a comparison of neutral vs maximal anatomical external rotatory states. J Arthroplast. 2017;32(6):2005-11.

47. Herschmiller T, Grosso MJ, Cunn GJ, Murtaugh TS, Gardner TR, Geller JA. Step-wise medial collateral ligament needle puncturing in extension leads to a safe and predictable reduction in medial compartment pressure during TKA. Knee Surg Sports Traumatol Arthrosc. 2018;26(6):1759-66.

48. Gaudiani MA, Knapik DM, Kaufman MW, Salata MJ, Voos JE, Karns MR. Percutaneous superficial medial collateral ligament release outcomes during medial meniscal arthroscopy: a systematic review. Arthrosc Sport Med Rehabil. 2020;2(2):e153-9.

49. Walker PS, Meere PA, Bell CP. Effects of surgical variables in balancing of total knee replacements using an instrumented tibial trial. Knee. 2014;21(1):156-61.

50. Gustke KA, Golladay GJ, Roche MW, Jerry GJ, Elson LC, Anderson CR. Increased satisfaction after total knee replacement using sensor-guided technology. Bone Joint J. 2014;96B(10): 1333-8.

51. Meneghini RM, Ziemba-Davis MM, Lovro LR, Ireland PH, Damer BM. Can intraoperative sensors determine the "target" ligament balance? Early outcomes in total knee arthroplasty. J Arthroplast. 2016;31(10):2181-7.

52. Meere PA, Schneider SM, Walker PS. Accuracy of balancing at total knee surgery using an instrumented tibial trial. J Arthroplast. 2016;31(9):1938-42. 
53. Chu LM, Meere PA, Oh C, Walker PS. Relationship between surgical balancing and outcome measures in total knees. Arthroplast Today. 2019;5(2):197-201.

54. Jacobs CA, Christensen CP, Karthikeyan T. Greater medial compartment forces during total knee arthroplasty associated with improved patient satisfaction and ability to navigate stairs. J Arthroplast. 2016;31(9):87-90.

55. Verstraete MA, Meere PA, Salvadore G, Victor J, Walker PS. Contact forces in the tibiofemoral joint from soft tissue tensions: implications to soft tissue balancing in total knee arthroplasty. J Biomech. 2017;58:195-202.

56. Shelton TJ, Howell SM, Hull ML. Is there a force target that predicts early patient-reported outcomes after kinematically aligned TKA? Clin Orthop Relat Res. 2019;477(5):1200-7 Study examining variety of published force targets which found no association with outcome in patients undergoing kinematically aligned TKA. This raises the question as to whether these thresholds are clinically valid.

57. Held MB, Grosso MJ, Gazgalis A, Sarpong NO, Boddapati V, Neuwirth A, Geller JA. Improved compartment balancing using a robot-assisted total knee arthroplasty. Arthroplast Today. 2021;7: $130-4$.

58. Song SJ, Lee HW, Il KK, Park CH. Load imbalances existed as determined by a sensor after conventional gap balancing with a tensiometer in total knee arthroplasty. Knee Surgery, Sport Traumatol Arthrosc. 2020;28(9):2953-61.

59.• Wood TJ, Winemaker MJ, Williams DS, Petruccelli DT, Tushinski DM, de Beer J de V. Randomized controlled trial of sensor-guided knee balancing compared to standard balancing technique in total knee arthroplasty. J Arthroplast. 2021;36(3):953-7 Level I study demonstrating no significant difference in outcomes following sensor-guided knee balancing compared to standard techniques.
60. Krell E, Joseph A, Nguyen J, Gonzalez Della Valle A. Small soft tissue tension changes do not affect patient-reported outcomes one year after primary TKA. Int Orthop. 2021;45(1):139-45.

61. Chang JS, Kayani B, Wallace C, Haddad FS. Functional alignment achieves soft-tissue balance in total knee arthroplasty as measured with quantitative sensor-guided technology. Bone Joint J. 2021;103-B(3):507-14.

62. Livermore AT, Erickson JA, Blackburn B, Peters CL. Does the sequential addition of accelerometer- based navigation and sensor- guided ligament balancing improve outcomes in TKA? Bone Jt J. 2020;102(6):24-30.

63. Manning WA, Blain A, Longstaff L, Deehan DJ. A load-measuring device can achieve fine-tuning of mediolateral load at knee arthroplasty but may lead to a more lax knee state. Knee Surg Sports Traumatol Arthrosc. 2019;27(7):2238-50.

64. MacDessi SJ, Cohen DA, Wood JA, Diwan AD, Harris IA. Does the use of intraoperative pressure sensors for knee balancing in total knee arthroplasty improve clinical outcomes? A comparative study with a minimum two-year follow-up. J Arthroplast. 2021;36(2): 514-9.

65. Golladay GJ, Bradbury TL, Gordon AC, Fernandez-Madrid IJ, Krebs VE, Patel PD, Suarez JC, Higuera Rueda CA, Barsoum WK. Are patients more satisfied with a balanced total knee arthroplasty? J Arthroplast. 2019;34(7):S195-200.

66. Amundsen S, Yu LY, González Della Valle A. Algorithmic piecrusting of the medial collateral ligament guided by sensing technology affects the use of constrained inserts during total knee arthroplasty. Int Orthop. 2017;41(6):1139-45.

Publisher's note Springer Nature remains neutral with regard to jurisdictional claims in published maps and institutional affiliations. 